\title{
Ballistic Impact Energy Absorption of Light Protection Blankets
}

\author{
Gerardus Janszen*, Davide Lietti, Maurizio Lualdi, Giorgio Novati, Luca Di Landro
}

Politecnico di Milano, Piazza Leonardo da Vinci 32, Milan 20133, Italy

Corresponding Author Email: gerardus.janszen@polimi.it

https://doi.org/10.18280/ijsse.100116

Received: 17 June 2019

Accepted: 5 August 2019

\section{Keywords:}

ballistic tests, dry composite materials,

Kevlar, mine, protection, static tests, weapon

\begin{abstract}
In present times, security procedures against firearms attack have unfortunately gained large relevance even in non-war environment. The use of protections against terrorist events is now being considered also in the design and construction of public spaces and buildings as well as civil vehicles and aircrafts. The chance of employing efficient, yet non-invasive and low-cost solutions, at least against light weapons and or small explosives, can significantly extend the safety levels in different environments commonly accessible. Bulletproof rolling curtains, light and fixed or movable walls, anti-intrusion/anti-projectile doors, explosion-resistant containment bags are only few examples of relevant applications which have raised interest either by research and industry. In this research, the ballistic protection efficiency of light and flexible systems, which may be integrated in different components, with capacity of shielding from small weapons or blasts, was investigated. In view of approaching optimized arrangements, different configurations of multilayer fabrics were tried in ballistic tests with projectiles ranging from steel balls to firearm bullets. Test blankets with different number of plies, orientation, and areal weight were selected; sandwich configurations and the insertion of inter-ply materials were also analyzed. Particular attention was dedicated to the relevance of different energy absorption mechanisms over the projectile impact protection response in view of their efficiency improvement. Numerical methods for the analysis of bullet impacts and deformation contributes were also approached and discussed.
\end{abstract}

\section{INTRODUCTION}

The traditionally military peculiarity of battlefields, which engaged more or less defined locations, weapons and soldiers, have dramatically evolved in present times into terrorist events usually involving civil locations and unarmed and unprepared human being. In present times, the actual chance to avoid or reduce threats in such events occurring in civil environments, as for instance public buildings, public conventions locations or even con-fined spaces (such as airplanes or a train wagons), is largely assigned to active prevention and/or access control measures. Such measures are certainly efficient in decreasing the chance of employment of heavy weapons or large amounts of explosives but may result scarcely effective for the detection of light firearms. Recent examples, with particularly dramatic outcomes, of attacks in theaters, museums, schools, religious spaces, public gathering areas have pointed out the limits of such solutions. It can be noted that, in civil locations, quite little actions are dedicated to the implementation of passive measures, which can operate right before or during the occurrence of a terrorist attack. The availability and extensive use of efficient, yet non-invasive and low-cost protections which can be integrated in existing or new structural or architectonic elements may provide shielding elements and thus extend the safety levels at least against light weapons and/or small explosives in different environments commonly accessible to the public. Bullet-proof rolling curtains, light and fixed or movable walls, anti-intrusion/anti-projectile doors, explosion-resistant containment bags are only few examples of relevant applications which have raised interest either by research and industry. Some of these systems have been proposed in specific situations [1], but in general, their employment is not yet widespread in present times. The design, materials selection and testing of ballistic protections is usually addressed to solutions to be employed in police or military and peace-keeping scenarios. In these situations, protection from heavy weapons or large explosives are the target conditions, which require strong, thick and weighty armors to be applied to trained personnel, army vehicles or fixed locations. In this research, the ballistic protection efficiency of light and flexible systems, which may be integrated in different components, with capacity of shielding from small weapons or blasts, was investigated. In view of improving protection efficiency, while maintaining reduced weight and costs, different configurations of multilayer aramid fabrics were selected and tried in static and ballistic tests with projectiles ranging from steel balls to firearm bullets. Test blankets with different number of plies, orientation, areal weight, i.e. blanket weight/ unit area, were considered; hybrid configurations and the insertion of inter-ply materials were also analyzed.

In addition, a preliminary analysis to approach possible numerical modelling of a projectile impact against an aramid fabric was initiated. The impact response of continuous, isotropic materials, as metals, for instance, in projectile perforation is widely studied in the literature.

Numerical models to analyze the projectile perforation of multilayer fabrics have also been proposed, which evidenced difficulties related to the complex structure of fabrics, leading to necessity of extremely large computational capacity, unless approximating choices are made in the model construction [2].

In this paper, after the experimental campaign, the main 
aspects related to fabric characteristics, which may significantly affect the numerical analysis of the projectilefabric impact are reviewed, in order to point out the possible implications in prospected modelling. Aspects as geometry of woven fibers, interactions between threads and/or elementary filaments are thus discussed.

\section{EXPERIMENTAL: RESULTS AND DISCUSSION}

In the following paragraphs quasi-static puncture tests and ballistic tests are presented.

\subsection{Materials and sample production}

Two different Kevlar ${ }^{\circledR}$ fabrics were used in all the puncture tests for comparison [3, 4], while in the ballistic tests, only the Aramid Style 101 Water-Repellent Ballistic Fabric was used. The main characteristics of both fabrics are shown in Table 1.

Table 1. Technical data for the two fabrics $[5,6]$

\begin{tabular}{ccc}
\hline & $\begin{array}{c}\text { SAATILAR } \\
\text { STYLE 101 }\end{array}$ & CT 709 \\
\hline $\begin{array}{c}\text { Warp and weft } \\
\text { material }\end{array}$ & $\begin{array}{c}\text { Kevlar® } 29- \\
3300 \mathrm{dtex}\end{array}$ & $\begin{array}{c}\text { Twaron }{ }^{\circledR}- \\
\text { 930dtex }\end{array}$ \\
\hline Weaving style & Plain weave & Plain weave \\
\hline $\begin{array}{c}\text { Areal weight (fabric } \\
\text { weight/unit area) }\end{array}$ & $460 \mathrm{~g} / \mathrm{m}^{2} \pm 4 \%$ & $200 \mathrm{~g} / \mathrm{m}^{2} \pm 4 \%$ \\
\hline Construction & $6,7 \times 6,7 \pm 0,3$ & $\begin{array}{c}10,5 \times 10,5 \pm 0,3 \\
\text { threads } / \mathrm{cm}\end{array}$ \\
\hline threads/cm & $2800 \mathrm{~N} / \mathrm{cm} \mathrm{min.}$ & $1400 \mathrm{~N} / \mathrm{cm}$ \\
\hline Tensile strength & $630 \mu \mathrm{m} \pm 15 \%$ & $300 \mu \mathrm{m} \pm 15 \%$ \\
\hline Thickness & &
\end{tabular}

For a faster identification of the material the two fabrics will be referred to as K460 and T200; the letter identifying the yarns material and the number referring to the areal weight of the fabric.

A frame to support the specimens, designed to prevent fabric slipping, was used to clamp the multilayer system, with up to 8 layers of both the type of fabrics. The free testing area for both the punch and the ballistic tests was $100 \times 100 \mathrm{~mm}$.

\subsection{Puncture test}

In order to reduce the number of ballistic tests, which are time consuming, some information about the behavior of fabrics, can be achieved with a puncture test [7, 8]. Simple tensile tests, which give good information on the strength of the material, are not sufficient to observe pull-out, fibrillation, windowing, which are a consequence of a ballistic impact.

On the other end in a puncture test, which is quasi-static, a punch with the shape of a projectile is pushed into the fabric and the dynamic of the impact is reproduced at least for what concerns the geometry. The test can give information about windowing, frictional effects and a thorough insight of the failure mechanisms of the material.

In the tests, two different punches were used: one with a spherical head with a diameter of $10 \mathrm{~mm}$ and another with a square flat head of $10 \times 10 \mathrm{~mm}$. The spherical punch obviously reproduces the shape of a classical projectile. The diameter of the spherical punch was chosen to be equal to the diameter of the projectile used in the ballistic impact test. The flat head punch was used in order to explore the possibility to gather other information about the material.
The fabrics were mounted in the clamp, keeping the orientation of the yarns with a known direction. The bolts were all fastened with the same torque of $20 \mathrm{Nm}$. The testing machine was an MTS 858 Mini Bionix II with a maximum force of $15 \mathrm{kN}$. The velocity of the ram was set to $10 \mathrm{~mm} / \mathrm{min}$ and the data acquisition frequency to $20 \mathrm{~Hz}$. Figure 1 shows the experimental test set-up.

The tests were conducted on single layers and on combinations of two single layers with the two type of fabrics. Additional tests were performed with samples impregnated with a lubricant [9-11], and with layers in which the warp and weft yarns were angled by $45^{\circ}$ [12]. The lubricant was a silicone oil with a viscosity of $100 \mathrm{cP}$. Table 2 shows the complete list of the samples.

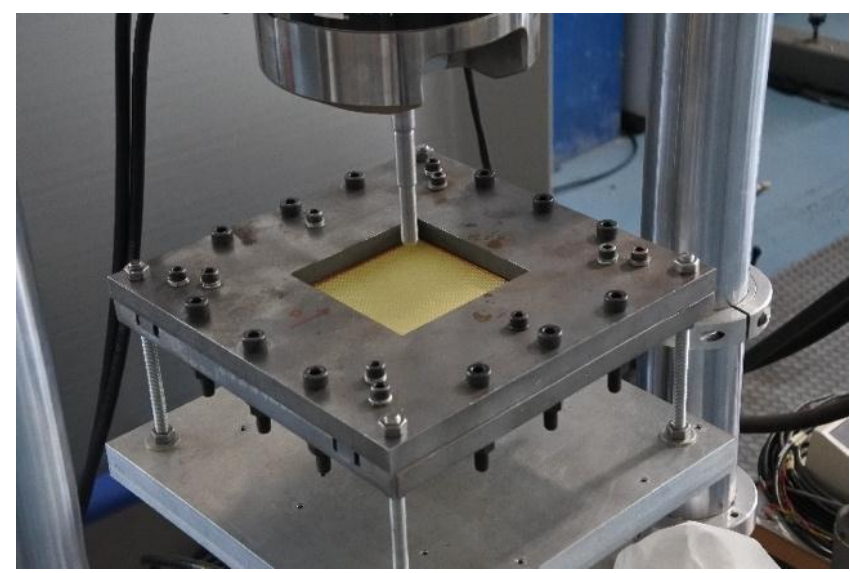

Figure 1. Test set up

Table 2. List of samples for quasi-static test

\begin{tabular}{|c|c|c|}
\hline $\begin{array}{c}\text { SPHERICAL } \\
\text { PUNCH }\end{array}$ & $\begin{array}{l}\text { SQUARE } \\
\text { PUNCH }\end{array}$ & ADDITIONAL TESTS \\
\hline $\begin{array}{l}\text { 1L-K460 } \\
\text { (1 layer) }\end{array}$ & $\begin{array}{l}\text { 1L-K460 } \\
\text { (1 layer) }\end{array}$ & $\begin{array}{c}\text { Square punch_K460+oil } \\
\text { (1 layer) }\end{array}$ \\
\hline $\begin{array}{l}\text { 1L-T200 } \\
\text { (1 layer) }\end{array}$ & $\begin{array}{l}\text { 1L-T200 } \\
\text { (1 layer) }\end{array}$ & $\begin{array}{c}\text { Square punch_T200+oil } \\
\text { (1 layer) }\end{array}$ \\
\hline $\begin{array}{l}\text { 2L-K460 } \\
\text { (2 layers) }\end{array}$ & $\begin{array}{l}\text { 2L-K460 } \\
\text { (2 layers) }\end{array}$ & $\begin{array}{c}\text { Spherical punch_2L- } \\
\text { K460_Angled } \\
\text { (2 layers) }\end{array}$ \\
\hline $\begin{array}{l}\text { 2L-T200 } \\
\text { (2 layers) }\end{array}$ & $\begin{array}{l}\text { 2L-T200 } \\
\text { (2 layers) }\end{array}$ & $\begin{array}{c}\text { Spherical punch_2L- } \\
\text { T200_Angled } \\
\text { (2 layers) }\end{array}$ \\
\hline $\begin{array}{c}\text { 2L-T200K460 (2 } \\
\text { layers })\end{array}$ & $\begin{array}{c}\text { 2L-T200K } 460 \\
\text { (2 layers) }\end{array}$ & \\
\hline $\begin{array}{c}\text { 2L-K460T200 (2 } \\
\text { layers })\end{array}$ & $\begin{array}{l}\text { 2L-K460T } 200 \\
\text { (2 layers })\end{array}$ & \\
\hline
\end{tabular}

The results obtained with the spherical punch are shown in Figure 2. These are more significant because the shape of the punch gives similar effects observed in ballistic tests. The overall shape of the curves follows a specific trend. The initial displacement without force increase is due to the fact that the punch is brought in contact with the surface of the specimens. The force starts to rise with a slope that is determined by the characteristics of the panel that is tested. A peak force is reached after which the force drops almost to zero as the punch passes through the fabrics. The penetration and the force drop are consequence of the local failure of the yarns in contact with the punch and as a consequence of the windowing effect for which the yarns are moved aside.

It can be observed that when the number of layers increases, with both the types of fabric, the load increases earlier, the 
maximum value is almost doubled and the corresponding displacement higher, hence the total deformation energy is more than doubled. The reason relies on the mutual effect that multiple layers have on the structure of each other.

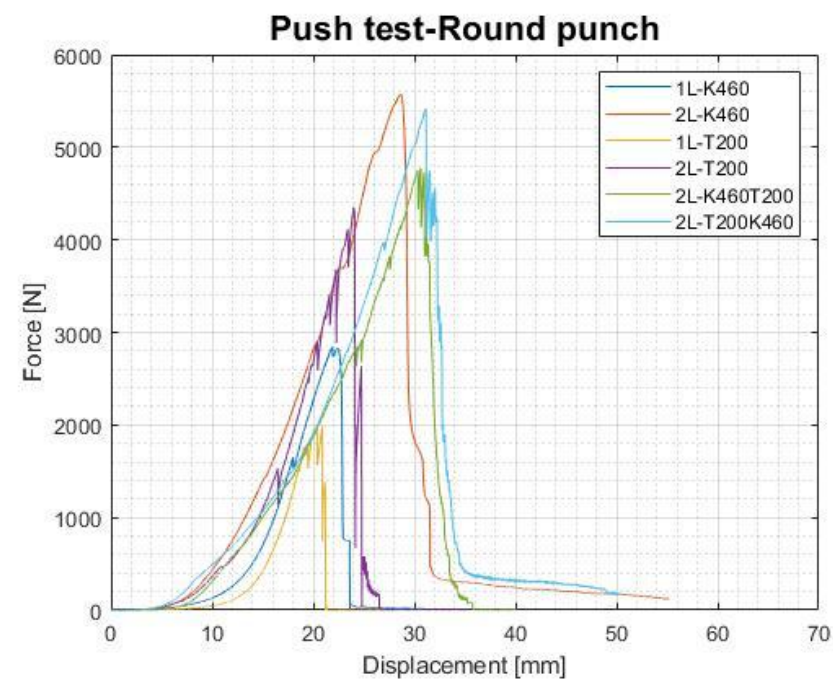

Figure 2. Results for the spherical punch

Table 3. Numerical values from quasi-static tests of the panels

\begin{tabular}{cccc}
\hline & $\begin{array}{c}\text { PEAK } \\
\text { FORCE } \\
{[\mathrm{KN}]}\end{array}$ & $\begin{array}{c}\text { MAX. } \\
\text { DISPLACEMENT } \\
{[\mathrm{mm}]}\end{array}$ & $\begin{array}{c}\text { SEA } \\
{\left[\mathrm{J} /\left(\mathrm{g} / \mathrm{m}^{2}\right)\right]}\end{array}$ \\
\hline 2L-K460 & 5,6 & 28,7 & 0,064 \\
\hline 2L-T200 & 4,4 & 24,0 & 0,068 \\
\hline 2L-T200K460 & 5,4 & 31,1 & 0,079 \\
\hline 2L-K460T200 & 4,7 & 30,6 & 0,070 \\
\hline
\end{tabular}

The specific energy absorption (SEA) is defined as the energy of deformation divided by the areal weight of the panel expressed in $\mathrm{g} / \mathrm{m}^{2}$, that is given by the sum of the areal weight of the layers used in each panel. It is of course necessary to evaluate the specific energy absorption normalized to the weight as the weight is a crucial feature of antiballistic protections.

It is worth to point out that in the combination $2 \mathrm{~L}$ T200K460 almost the same maximum load as in the 2L-K460 is reached, but with a smaller areal weight. This is confirmed also when the SEA is calculated (Table 3 ), in which the $2 \mathrm{~L}$ T200K460 combination show the highest value.

Table 3 lists the numerical values obtained from the tests. The calculation of the energy is stopped at the peak force because the second part of the curve, where the force drops almost to zero, is only determined by the friction of the punch with the fabrics.

The tests with the square punch gave very different results when compared with the corresponding tests with the spherical punch. Results of these tests were considered not useful and not reliable, because a rupture in correspondence of the clamp was observed, mainly due to a higher slippage of the fabrics in the clamping systems.

Two additional tests were carried out with the specimens been impregnated with a silicone oil for 5 minutes. The results show a slight decrease of the slope of the force-displacement curve due to the lubricant effect. No permeation was noted on the K460 while the T200 showed a high capillarity through the thickness and sideways.
The tests performed on panels having two layers angled between them confirmed the results obtained in literature that angled plies have a greater energy absorption. This is because the difference in orientation of the plies causes a more even distribution of the load, so the load is not concentrated on the principal yarns only.

The results in term of type of failure obtained with the two punches are very different. The main difference is of course in the contact between the surface of the punch and the fabrics. The square punch engages substantially the same number of yarns that are found in an area equal to that of the punch, approximately 5 for the K460 and 9 for the T200. On the contrary, the round punch contacts directly less yarns, pushing aside the other yarns. This is the reason for the lower peak force reached in the spherical punch tests: the square punch in fact loads more yarns, hence the force is distributed and the stress is lower in each yarn. In the spherical punch case, due to the windowing effect, only a couple of yarns remain in front of the punch and the load is consequently higher. With the spherical punch the yarns that are contacted and not pushed aside assume a flattened shape and spread around the punch itself during the test. Figure 3 shows the different behavior of the two types of punches.
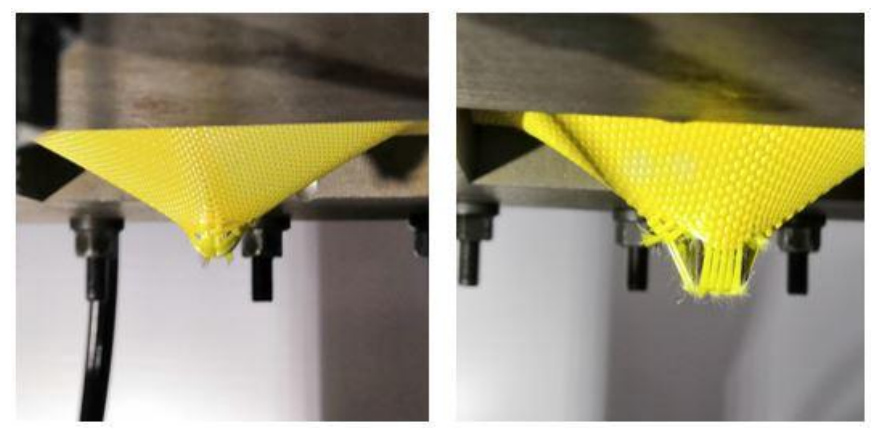

Figure 3. Comparison of effect on the fabric of the two punches (spherical on the left)

\subsection{Ballistic tests}

Ballistic tests were performed using an in-house device, which allows to shoot steel balls with diameters ranging from 2 to $20 \mathrm{~mm}$ at a speed up to about $200 \mathrm{~m} / \mathrm{s}$. The equipment is composed of a chamber pressurized at about 7 bars, directly connected to a long aluminum tube (length 7 meters, internal diameter $40 \mathrm{~mm}$, external diameter $70 \mathrm{~mm}$ ). The pressurized chamber and the tube are separated by a $0.075 \mathrm{~mm}$ thick metal foil; an electronic switch activates a sharp point toward the metal foil, which on breaking, allows the expansion of the compressed air and the acceleration of high-density polyethylene (HDPE) sabot, carrying the steel ball projectile, inside the aluminum duct. At the end of the conduit a dissipative aluminum stopper blocks the sabot travel, while the projectile is launched against a target placed at about $50 \mathrm{~cm}$ after the tube exit [13].

A high velocity Phantom v5.1 video camera was used to measure the projectile's speed before and after the impact, thus allowing to follow the fabric perforation or the ball rebound event and estimate the kinetic energy lost by the projectile. In Figure 4, the schematic of the ballistic test set-up is shown.

Different number of plies and different orientations were used. In some tests a layer of nitrile rubber was added between the first and the second plies and in some cases a repetition of the shot was carried out on the same specimens (Table 4). 
Analyzing the data form the high-speed camera, the impact velocity and the exit or rebound velocity were calculated to obtain the energy absorbed during the impact. Figure 5 shows the differences between Vout (Figure 5 (a)) and Vreb (Figure 5(b)) are shown.

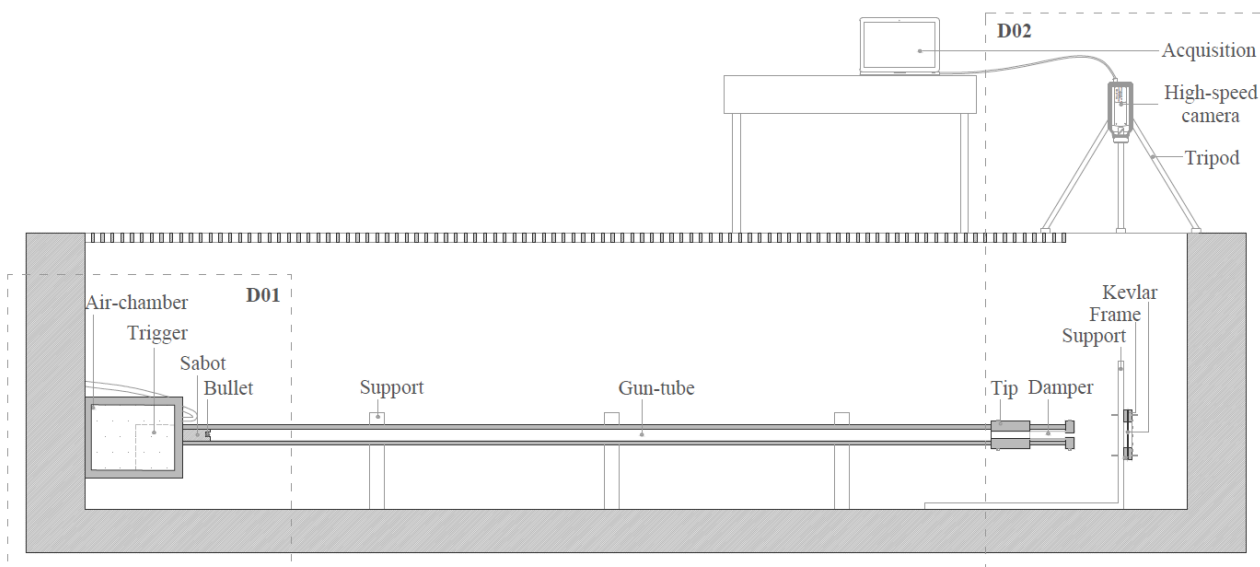

Figure 4. Ballistic test set up

Table 4. List of tests and number of shots * Presence of a nitrile rubber layer

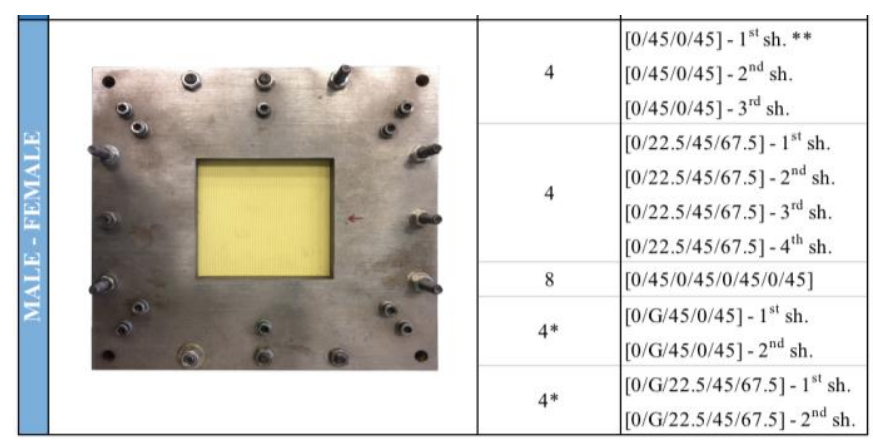

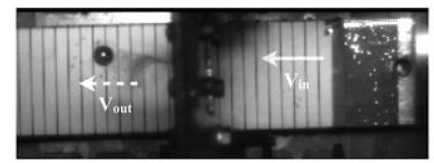

(a)

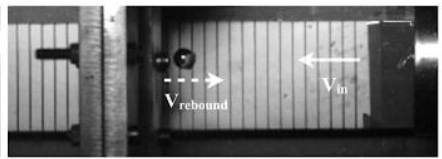

(b)
Figure 5. Screen shots from high-speed camera. (a) Bullet passing through; (b) Bullet being rebound

In Table 5 the results of the tests are shown. It can be noticed that from an energy point of view the ply orientation $[0 / 22,5 / 45 / 67,5]$ seems to be the best configuration.

As expected, the results clearly show that an increase in the number of plies increases the capability of the specimen to hold the bullet. In all the test with only two layers of fabric, the bullet passed the specimen with a small change of the impact velocity. Increasing the number of plies, the number of shots needed for full perforation increased as well.

Also ply orientation remarkably affects the behavior of the specimen and the orientation $[0 / 22.5 / 45 / 67.5]$ seems to be the best four-plies configuration among those tested. The presence of rubber seems not to significantly enhance the perforation resistance; however, at the moment, no conclusive results can be drawn for this configuration and additional tests are required. In case of 8 plies, the configuration [0/45]4 seems to be well adequate to contain the projectiles in lab conditions.

Following ballistic tests in lab, specimens made of 8 and 16 plies $([0 / 45] 4$ or 8$)$ were tested in a shooting range using different firearms and bullets.

Shots at about $310 \mathrm{~m} / \mathrm{s}$ with about-spherical head bullets (45 ACP, $9.55 \mathrm{~mm}$ diameter) resulted well contained with 16 plies and in most cases, also with 8 plies. Even in case of perforation, which occurred usually with repeated shots, a consistent loss of kinetic energy was evident in all cases, even if it could not be measured.

Table 5. List of tests and results

* velocity is low but still taken into account. 'no' means no

\begin{tabular}{|c|c|c|c|c|c|}
\hline$[0 / 45 / 0 / 45] \times 1$ & 212 & 33 & - & 260 & no \\
{$[0 / 45 / 0 / 45] \times 2$} & 185 & 45 & - & 191 & only $4^{\text {th }}$ ply \\
yes \\
{$[0 / 45 / 0 / 45] \times 3$} & 210 & - & 48 & 248 & no \\
\hline$[0 / 22.5 / 45 / 67.5] \times 1$ & 200 & 30 & - & 232 & no \\
{$[0 / 22.5 / 45 / 67.5] \times 2$} & 175 & 40 & - & 172 & no \\
{$[0 / 22.5 / 45 / 67.5] \times 3$} & $140^{*}$ & $57^{*}$ & - & $97 *$ & no \\
{$[0 / 22.5 / 45 / 67.5] \times 4$} & 210 & 46 & - & 249 & no \\
\hline$[0 / 45 / 0 / 45 / 0 / 45 / 0 / 45]$ & 210 & 55 & - & 244 & Only $1^{\text {st }}$ ply \\
\hline$[0 / \mathrm{G} / 45 / 0 / 45] \times 1$ & 170 & 27 & - & 167 & stuck in rubber \\
{$[0 / \mathrm{G} / 45 / 0 / 45] \times 2$} & 210 & - & 0 & 262 & Only $1^{\text {st }}$ ply \\
\hline$[0 / \mathrm{G} / 22.5 / 45 / 67.5] \times 1$ & 210 & 16 & - & 260 & yes \\
{$[0 / \mathrm{G} / 22.5 / 45 / 67.5] \times 2$} & 210 & - & 82 & 222 & \\
\hline
\end{tabular}




\section{NUMERICAL MODELLING}

A numerical modelling of a woven fabric textile specimen was investigated. The difficulty to create this model is not only related to the dynamic aspect but also to the configuration and the geometry of the material. Being a textile, it cannot be considered as a uniform element. From literature, two different approaches are possible: a macroscopic modeling approach and a discrete mesoscopic modeling approach [14]. In the first type of modelling, the composites are treated as membrane or shell elements modelled as continuum. In the second case individual components, like fibers or yarns, are modelled as 1D elements and the shear behavior of the matrix with 2-D shell elements; these are overlaid with shared nodes. This approach normally requires the development of a user-defined material for the constitutive shear behavior and simulation can be done in finite element packages such as ABAQUS ${ }^{\circledR}$ and LSDYNA ${ }^{\circledR}$. Due to the complexity of the problem, it was decided to study simple cases that can represent a part of the general problem. The following steps are hypoth-esized: 1) the dynamic aspect, considering a bullet impact with a metal plate in ABAQUS; 2) the composite lay-up function using ABAQUS; 3) the woven fabric model using ABAQUS; 4) the woven fabric model using LS-DYNA. The results of the first step are easy to find in literature and point out the main parameters that affect the ballistic impact modelling: projectile velocity, mass and geometry, boundary conditions, target thickness, target yield strength, failure strain and friction between the two elements. The last, which is easy to characterize in case of a homogeneous material, represents the biggest problem when modelling a Kevlar fabric. The material's properties that have to be set as inputs, depend on too many physical factors, like the dimension of the fibers, the number of the fibers, the number of yarns. The remaining three steps will be investigated using the data obtained from the puncture tests and the ballistic tests.

\section{CONCLUSIONS}

The ballistic protection efficiency of Kevlar woven fabric blankets was investigated. Different configurations of multilayer fabrics were tested with puncture and ballistic tests. Puncture tests were useful to observe the failure mechanisms and to study the effect when different fabrics are used in ballistic protection.

Test results showed the feasibility to enhance bullet protection. The number of plies, the fiber orientation, and the areal weight influence the general behavior. In particular when the number of plies is greater than even in case of multiple shots, no perforation was observed or, in the worst case, a great reduction in the kinetic energy was achieved. The latter would result in a lower lethal injury risk.

A numerical modelling approach was supposed to help in a better understanding of the local effects during impact. Simple case studies have been identified and one of the main difficulties seems to be characteristics of the woven fabric and the good simulation of the friction between the bullet and the fabric fibers.

More ballistic test will be carried out and a deeper understanding of the role of the friction will be useful in a first approximated model of the impact.

\section{ACKNOWLEDGMENT}

The financial support of PoliMine in the frame of Polisocial projects by Politecnico di Milano is acknowledged. The authors wish to thank A. Barbieri and M. Fumagalli Romario for their help in experimental tests.

\section{REFERENCES}

[1] Navin, D., Ostman, J.R.E., Lewis, P., Tamulonis, F. (2018). Ballistic Curtain Cordon System. U.S. Pat. Appl. 20180156577. http://www.fly-bag.eu/

[2] Sun, D., Chen, X., Lewis, E., Wells, G. (2012). Finite element simulation of projectile per-foration through a ballistic fabric. Textile Research Journal, 83(14): 14891499. https://doi.org/10.1177/0040517512464295

[3] Figucia, F. (1990). Energy absorption of Kevlar fabrics under ballistic impact. U.S. Army Natick Research and Development Command.

[4] Bajaj, P. (1997). Ballistic protective clothing: An overview. Indian Journal of Fibre and Textile and Reasearch, 22: 274-291.

[5] SAATI, Fabric Data Sheet of SAATILAR STYLE 101 WATERREPELLENT, 2018.

[6] PRO-SYSTEMS SPA, SCHEDA TECNICA CT 709, 2010.

[7] Shockey, D., Erlich, D.C., Simons, E.J.W. (2001). Improved Barriers to Turbine Engine Fragments: Interim Report III.

[8] Briscoe, B.J., Motamedi, E.F. (1992). The ballistic impact characteristics of aramid fabrics: The influence of interface friction. Wear, 158(1-2): 229-247. https://doi.org/10.1016/0043-1648(92)90041-6

[9] Nilakantan, G., Merrill, R.L., Keefe, M., Gillespie Jr, J.W., Wetzel, E.D. (2015). Experimental investigation of the role of frictional yarn pull-out and windowing on the probabilistic impact response of Kevlar fabrics. Composite: Part B, 68: 215-229. https://doi.org/10.1016/j.compositesb.2014.08.033

[10] Nilakantan, G., Gillespie Jr, J.W. (2013). Yarn pull-out behavior of plain woven Kevlar fabrics: Effect of yarn sizing, pullout rate, and fabric pre-tension. Composite Structures, 101: 215-224. https://doi.org/10.1016/j.compstruct.2013.02.018

[11] Bazhenov, S. (1997). Dissipation of energy by bulletproof aramid fabric. Journal of Materials Science, 32(15):

4157-4173. https://doi.org/10.1023/a:1018674528993

[12] Wang, Y., Chen, X., Young, R., Kinloch, I., Garry, W. (2016). An experimental study of the effect of ply orientation on ballistic impact performance of multi-ply fabric panels. Textile Research Journal, 86: 34-43. https://doi.org/10.1177/0040517514566110

[13] Janszen, G., Capezzera, G., Grande, A.M., Di Landro, L. (2019). Mitigation of impact damage with self-healing and anti-sloshing materials in aerospace fuel tanks. Aerospace, 6(2): 14 . https://doi.org/10.3390/aerospace6020014

[14] Tudor, J., Ma, L., Zawisza, J. (2016). An evaluation of the *FABRIC Material Model in ABAQUS/EXPLICIT for composite preforming analysis suitability. American Society of Composites-31st Technical Conference. 